\title{
Kindergarten und Operationssaal
}

\section{Jörg Nef}

Dr. med., Facharzt für Chirurgie, Mitglied FMH

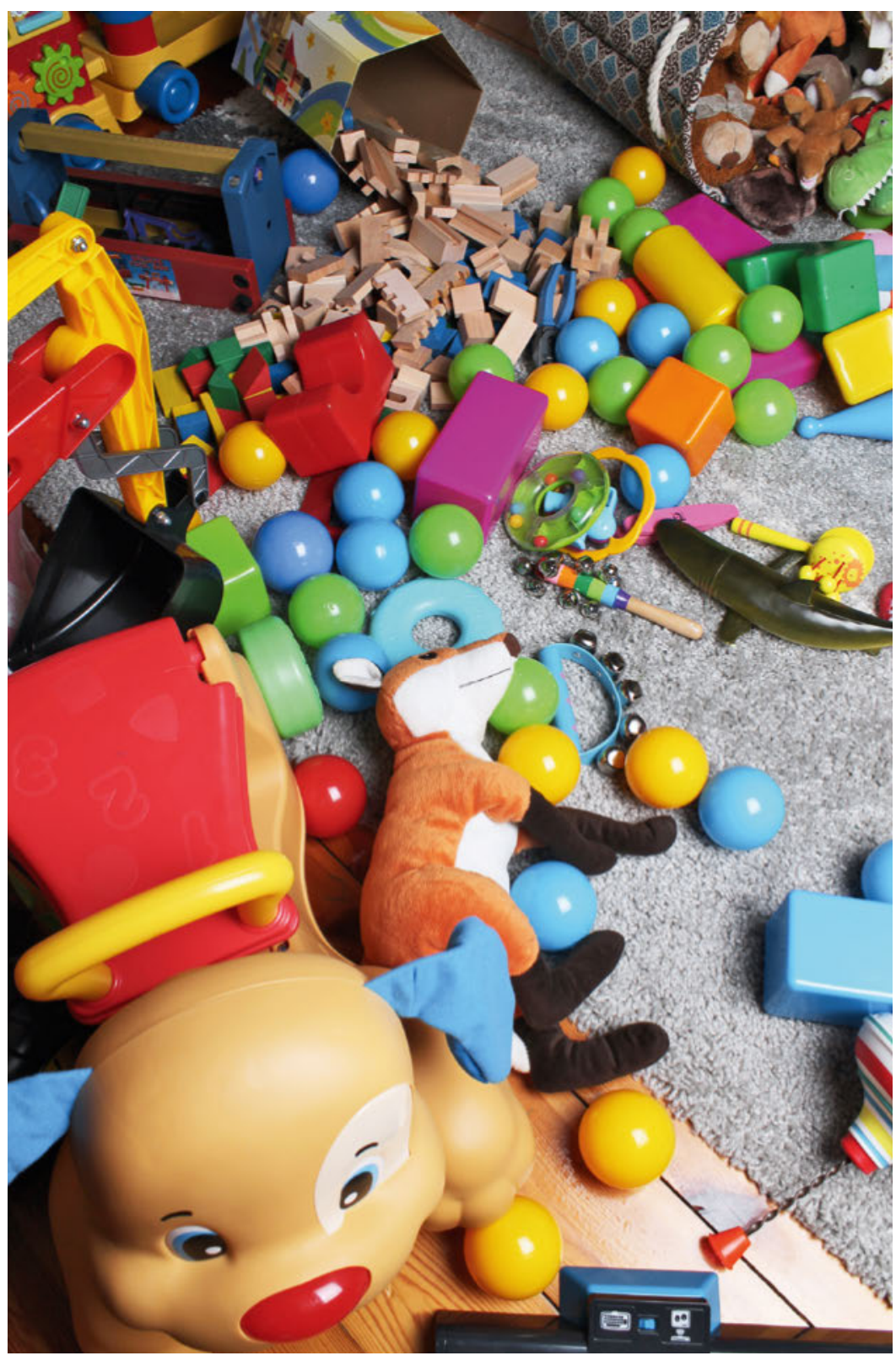

Es war in der zweiten Hälfte der 70er Jahre des vergangenen Jahrhunderts. Seit Kurzem war ich Chefarzt an einem Ostschweizer Landspital und fühlte mich auf der Höhe meiner chirurgischen Schaffenskraft. DienstWochenende. Die üblichen Sonntagabend-Notfälle blieben diesmal aus. Ich war zu Hause und brachte unseren kleinen Sohn zu Bett. Er stand kurz vor dem Eintritt in den Kindergarten.

Der Boden des zugegeben kleinen Kinderzimmers war übersät mit Spielzeug. Kleine Autos, Tiere, Bauklötze und Püppchen behinderten jeden Schritt, und ich musste aufpassen, dass ich keinen der allesamt sehr wichtigen Gegenstände auf der Spielwiese zertrat. Ich ermahnte deshalb den Bewohner des Zimmers, nach dem Spielen besser aufzuräumen, und erwähnte den auf ihn zukommenden Kindergarten, in welchem man nach dem Spielen beim Platz mit den Bauklötzen, beim Platz mit der Brio-Eisenbahn oder dem «BäbistubenPlatz» und beim Platz mit dem Käuferladen wieder aufräumen müsse. Sonst schicken sie dich wieder. Die Antwort des Kleinen liess keinen Moment auf sich warten: «Dich schicken sie auch, wenn du falsch operierst ...»

Ich schluckte leer. Zusammen sangen wir das Kinderlied vom Engelein, das zu ihm kommt und am Bettchen Acht gibt. Ich verliess nach dem Gutenachtkuss kleinlaut das Zimmer und staunte, mit welcher Klarheit unser kleiner Sohn das "Kerngeschäft» meiner ärztlichen Spitaltätigkeit erkannt und in Form einer äusserst eindrücklichen "Retourkutsche» formuliert hatte.

Uns beiden ist es dann gut gegangen: Der Knirps konnte im Kindergarten bleiben und auch mich haben sie nicht geschickt!

\section{Bildnachweis}

๑ Monika3stepsahead | Dreamstime.com (Symbolbild) 